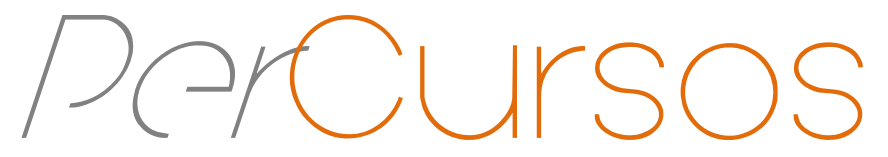

\title{
O casamento e a união estável são "o tesouro atrás do arco-íris"? Notas sobre família e conjugalidade no Brasil contemporâneo
}

\begin{abstract}
Resumo
Neste artigo, pretendo enfatizar o reconhecimento social e jurídico das relações conjugais entre pessoas do mesmo sexo, considerandoo como uma "política de reconhecimento" no Brasil. Procuro ainda demonstrar o percurso, desde o reconhecimento da união estável heterossexual como uma das possibilidades de família para o campo jurídico brasileiro, até a inclusão das conjugalidades entre pessoas do mesmo sexo neste conceito. Pretende discutir ainda como o judiciário poder dar visibilidade e reconhecimento há relações conjugais que já foram reconhecidas pelo meio social.
\end{abstract}

Palavras-chave: Conjugalidade. Casais do mesmo sexo.

Interdiciplinariedade.

\author{
Claudia Regina Nichnig \\ Doutorado Interdisciplinar pela \\ Universidade Federal de Santa \\ Catarina - UFSC. \\ claudianichnig@gmail.com
}

\footnotetext{
Para citar este artigo:

NICHNIG, Claudia Regina. O casamento e a união estável são "o tesouro atrás do arco-íris"? Notas sobre família e conjugalidade no Brasil contemporâneo. Revista PerCursos. Florianópolis, v. 14, n.27, jul./dez. 2013. p. 33-55.
}

\section{DOI: $10.5965 / 1984724614272013033$}

http: //dx.doi.org/10.5965/1984724614272013033 


\title{
The marriage and stable relationships are "the treasure behind the rainbow"? Notes about family and conjugality in contemporary Brazil.
}

\begin{abstract}
In this article I intend to describe the social and juridical recognition of conjugal relationships between same-sex couples by understanding it as a "politics of recognition" in Brazil. Furthermore, I trace a trajectory, starting from the recognition of a heterosexual stable union as one of the possibilities for establishing a family unit in the Brazilian juridical sphere, leading to full inclusion of conjugal relationships between same sex couples into that very framework. Finally, I wish to discuss how the legal system can render visible and recognize these conjugal relationships which are already recognized by the social sphere.
\end{abstract}

Keywords: Conjugality. Same-sex couples. Family. Interdisciplinarity. 
Neste artigo, pretendo enfatizar o reconhecimento social e jurídico das relações conjugais entre pessoas do mesmo sexo, considerando-o como uma "política de reconhecimento" (FRASER, 2010), marcada ou não pela aceitação por parte dos familiares, suas aproximações, seus distanciamentos, que tanto permeiam as relações conjugais homossexuais, através do debate a respeito dos significados da conjugalidade e da família no Brasil e como a legislação passou a reconhecer relações conjugais, passando de ilegítimas para relações legítimas, sob a proteção estatal.

Procuro demonstrar o percurso, desde o reconhecimento da união estável heterossexual como uma das possibilidades de família para o campo jurídico brasileiro, até a inclusão das conjugalidades entre pessoas do mesmo sexo neste conceito. Também irei traçar algumas considerações sobre como, nas classes populares, mas também nas elites brasileiras, as relações afetivo-conjugais são marcadas por arranjos e improvisações, enquanto a normatização pelo Estado passa a ser introduzida como a regra. Analiso a demanda pela introdução das relações afetivo-conjugais de casais do mesmo sexo na legislação e na possibilidade do registro e do casamento como um desejo de normalização, ao passo que arranjos familiares seguem sem normatização e que, mesmo sem qualquer legitimação estatal, são incluídos no conceito de família, no Brasil.

O caminho percorrido entre a promulgação da Constituição Federal de 1988, passando pela Lei 9278, de 10 de maio de 1996, que regulamentou a união estável entre um homem e uma mulher no Brasil, considerando "como entidade familiar, a convivência duradoura, pública e contínua, de um homem e uma mulher, estabelecida com objetivo de constituição de família"1 e o reconhecimento das uniões entre pessoas do mesmo sexo, também como entidade familiar, pode ser analisado dentro de um conjunto de transformações sociais, dentre as quais irei destacar as modificações nas legislações que visam regulamentar as relações conjugais no Brasil.

Antes de adentrar ao debate em torno do reconhecimento da união estável, é preciso analisar de que forma eram ou não regulamentadas estas relações conjugais. Até a Constituição de 1988 e a legislação que regulamentou a união estável em 1996, estes

1 Lei $n^{\circ}$ 9.278, de 10 de maio de 1996. Disponível em: www.planalto.gov.br. Acesso em: 28.09.2012. 
relacionamentos conjugais não originados através do casamento civil, eram considerados ilegítimos.

É preciso deixar claro que as relações conjugais antes de 1988, não originadas pelo casamento civil, estavam à margem da legislação brasileira. Sendo consideradas marginais, não eram reconhecidas como família e diante disso, não estavam sob a proteção da legislação. ${ }^{2}$ Estas relações conjugais eram conhecidas como concubinato, quando havia a previsão legal de impedimento para que esta relação passasse pelo crivo do casamento civil. O conceito de concubinato ainda está presente na legislação brasileira, em que o novo Código Civil de 2002, no título que trata da União Estável, estabelece no artigo 1727: "as relações não eventuais entre o homem e a mulher, impedidos de casar, constituem concubinato"', diferenciando o conceito de união estável, disposto no artigo 1723 já citado, do conceito de concubinato citado acima. A expressão da legislação "impedidos de casar", se refere a "relações adulterinas ou incestuosas" 4 , pois algumas pessoas, mesmo que impedidas de casar, como as separadas de fato ou judicialmente, podem constituir uniões estáveis.

Entretanto, vale lembrar que anteriormente ao reconhecimento judicial destas relações conjugais, recaía sob as chamadas concubinas, um forte estigma e preconceito social, não sendo reconhecidos a elas direitos, como a pensão alimentícia ou partilha de bens. Cabia, em alguns casos pagamento de uma indenização, "os direitos que comparavam a mulher concubina à serviçal doméstica" (MADALENO, 2011, p. 8) e nos casos em que havia a prova que os bens também foram adquiridos com esforço da chamada concubina esta "poderia reivindicar a divisão dos bens comuns em valor proporcional ao montante de seus efetivos aportes financeiros, pois seu vínculo afetivo era equiparado a uma sociedade de fato" (MADALENO, 2011, p. 8).

\footnotetext{
2 O direito de família está previsto na Constituição Federal, no Código Civil de 1916 e 2002, bem como em legislações esparsas.

3 Artigo 1727 da Lei 10406, de 10 de janeiro de 2002, Código Civil Brasileiro. Disponível em: www.planalto.gov.br. Acesso em: 29.10.2012.

40 conceito de adultério é objeto de decisões judiciais, em que mesmo que ainda exista controvérsia neste sentido, inúmeras decisões reconhecem atualmente a possibilidade da existência de união estável com pessoas casadas, rompendo paradigmas como o da monogamia. Marcos Alves da Silva afirma que a monogamia, a partir de uma perspectiva do Direito Civil-Constitucional não se constitui atualmente como um princípio estruturante do Direito de Família no Brasil, diante dos princípios constitucionais vigentes. (SILVA, 2013)
} 
Assim, sendo estas relações ilegítimas, os filhos/as nascidos destes casais também eram considerados ilegítimos e dentre as inúmeras consequências sociais e jurídicas, posso destacar a ausência de reconhecimento no direito sucessório, como por exemplo, a diferenciação entre os chamados filhos e filhas ilegítimos e os demais herdeiros e herdeiras. Então, somente eram reconhecidas as relações e, consequentemente, os filhos e filhas advindas da relação regrada pelo casamento. Fora desta norma estava a ilegitimidade. É preciso deixar claro que, até o ano de 1977, não havia a previsão legal do rompimento do casamento, que até então era indissolúvel, fazendo com que todas as relações conjugais não regulamentadas pelo casamento civil permanecessem desamparadas pela legislação, à margem de direitos.

Em minha dissertação de mestrado analisei as discussões acerca da implementação da Lei do Divórcio no Brasil (NICHNIG, 2008) sendo esta legislação reconhecida por Anette Goldberg como uma das principais iniciativas e medidas propostas pelo Estado brasileiro em relação às mulheres, no período de 1975-1979 (GOLDBERG, 1987, p.18).

Antes da lei do divórcio, que mesmo considerada por parte do discurso da época como uma lei desnecessária e elitista, a não possibilidade da total ruptura do vínculo conjugal (neste período havia apenas a figura do desquite) impedia que os desquitados pudessem ter seus novos relacionamentos (e os filhos e filhas advindos destes) como legítimos. Foi através das reivindicações destes casais, que tinham relacionamentos à margem da sociedade, que a lei brasileira que reconhecia apenas os vínculos formados pelo casamento, passa a ser questionada. Assim, a nova lei traz a figura da separação judicial e do divórcio, este sim, rompendo definitivamente o vínculo conjugal. Dentro do contexto jurídico, as relações conjugais marcadas pelos impedimentos ao casamento civil, eram chamadas de concubinato.

Os relacionamentos informais, que posteriormente foram intitulados como união estável, pela Constituição de 1988, eram conhecidos socialmente como amasiamento, em que as pessoas eram chamadas de amásias e amásios. Silvia Fávero Arend mostra como o amasiamento era uma prática comum para as classes populares brasileiras no final do Século XIX, período em que estudou a família popular em uma das capitais do sul do Brasil. Segunda a historiadora, para que o relacionamento fosse considerado um 
amasiamento "as pessoas deviam encontrar-se com alguma regularidade, a existência de responsabilidades mútuas entre homem e mulher, e a relação deveria ser pública, ou seja, parentes, vizinhos, amigos e outros tinham conhecimento da sua existência" (AREND, 2001, p. 61). O que a historiadora demonstra é que estar amasiado transformava-se, para estes casais, em uma das formas de estado civil para aqueles que viviam sob esta condição, ou seja, os amásios e amásias não se declaravam solteiros e solteiras e nem era identificados como tal pelo Judiciário e pelos operadores do direito, contexto estudado pela historiadora, mas era considerado "equivalente a um estado civil da ordem jurídica" (AREND, 2001, p. 61). Esta constatação perdura mesmo após o reconhecimento, pela ordem jurídica da união estável, ou seja, a união estável permanece sem alterar o estado civil dos contratantes, ambos permanecendo solteiros ou solteiras. A não mudança do estado civil traz consequências e status sociais diferentes do que aqueles dados ao casamento civil. Assim, enquanto no casamento civil os contratantes passam a ter o estado civil alterado de "solteiro" e "solteira” para "casado" e "casada", na união estável ambos permanecem "solteiro" e "solteira”, o que socialmente traz uma diferenciação. Segundo o estudioso do Direito, Silvio Venosa, o legislador novamente quis conceder uma diferença, considerando a união estável como uma segunda categoria (VENOSA, 2005).

Assim, ao mesmo tempo em que estes arranjos familiares informais não eram reconhecidos pelo Estado, ao estudar as famílias de classe média no Brasil, Carla Bassanezi afirma que a "família é tipicamente nuclear, com um número reduzido de filhos. Os padrões tradicionais de casamento estão com toda sua força até 1965. A autoridade máxima na família é conferida ao pai, o chefe da casa, e garantida pela legislação que incentiva o moralismo tradicional, a 'procriação', o trabalho masculino e a dedicação da mulher ao lar" (BASSANEZI, 1996, p. 49). Este padrão tradicional de casamento vai se constituindo como um modelo de convivência conjugal imposta pelo Estado, ao mesmo tempo em que variadas possibilidades de organização dos indivíduos em grupos familiares convivessem lado a lado ao contrato jurídico do casamento.

É importante ressaltar que uma grande parcela da população vivenciava relacionamentos informais, e que o modelo de família no Brasil nunca foi o modelo da família nuclear burguesa formada através do casamento civil. O reconhecimento jurídico 
da união estável passou a ser interessante para o Estado que visava introduzir estes casais na lógica da normalização, incentivando o casamento civil como o normal, o legal e o desejado. Silvia Fávero Arend (2001), e Marta de Abreu Esteves (1989) demonstraram, em suas pesquisas, que amasiar-se era a regra, enquanto que os casamentos foram sendo incentivados para a população brasileira, tornando-se uma prática imposta à população. Martha de Abreu Esteves, ao discorrer sobre as mulheres de camadas populares ofendidas em processos criminais de defloramento, na primeira metade do século XX, no Rio de Janeiro, afirmou que "não trocavam um amasiamento amoroso por um casamento formal" (ESTEVES, 1989, p. 119).

No período em que se discutiu a possibilidade do divórcio, eram recorrentes os embates entre divorcistas e antidivorcistas, dentre eles, a alegação de que o divórcio era importante somente para a parcela mais abastada da população, porque a nova lei não interessaria àqueles cidadãos e cidadãs que viviam na informalidade. Entretanto, para aqueles que se casavam, a possibilidade de poder desvincular-se para sempre daquela por quem não mais se nutria sentimentos de afeto, ou qualquer tipo de bons sentimentos, o divórcio acenava para a possibilidade de um novo casamento, fazendo com que estes casais que estavam à margem da lei, neste caso, os concubinos, pudessem adentrar a norma e ascenderem à condição social de "casados". Isso era considerado de extrema importância, pois na época, como já colocado, havia famílias consideradas legítimas e ilegítimas, diferenciando aqueles que tinham a possibilidade de se casar. Atualmente, pesquisas analisam as transformações familiares contemporâneas, como por exemplo, enfocando a paternidade após o divórcio (FINE; MARTIAL, 2012).

Através das práticas de um Estado intervencionista, mudanças significativas podem ser percebidas desde o início do século XX: novas legislações foram introduzidas, principalmente para regular as relações conjugais, o que pesava fortemente sobre as mulheres das camadas populares. Susan K. Besse (1999) afirma que os movimentos feministas da primeira onda no Brasil não atenderam às reivindicações das mulheres de classes populares, mas que se dedicaram às conquistas de novos direitos, principalmente 
para as mulheres de classe média ${ }^{5}$. Conforme Michel Foucault, as práticas do Estado visando regular o cotidiano dos sujeitos, atingindo mais fortemente as mulheres, faz-se presente nas sociedades ocidentais desde o século XVIII. Estas práticas são percebidas, por exemplo, através da multiplicação dos discursos sobre a proibição do sexo, impondo como e quando o sexo era permitido e pela imposição de práticas médicas e higiênicas (FOUCAULT, 1988, p. 9-49).

O que normatizava estas questões de família desde o início do Século XX era o Código Civil instituído em 1916, que regulou as relações conjugais e o direito de família, versando unicamente sobre as relações conjugais formadas através do casamento civil. 0 Código Civil de 1916 não trazia uma definição a respeito do que era reconhecido como uma relação conjugal, mas trazia a distinção entre a família ilegítima e a legítima, sendo esta última criada a partir do casamento civil, pois "o casamento legitima os filhos comuns, antes dele nascidos ou concebidos"6. Através desta legislação, depreende-se que o primeiro efeito jurídico do casamento é o de dar legitimidade à família.

Já em pesquisa recente, Cynthia Andersen Sarti demonstrou que este "padrão conjugal" não existe no Brasil, mesmo em camadas médias e altas, sendo que as famílias de camadas populares enfrentam ainda mais dificuldade para esta estabilidade conjugal provocada por "uniões instáveis e empregos incertos", o que prejudica "a existência da família, tal como a concebem" (SARTI, 2005, p. 11). O casamento, como normalizador deste padrão conjugal, é introduzido na sociedade brasileira como um ideal a ser perseguido e desejado, principalmente por parte das mulheres, mas que permanecesse sempre ao lado de famílias informais.

O reconhecimento da união estável foi aprovado na Lei $9278^{7}$, de 10 de maio de 1996, que alterou o artigo 226, parágrafo terceiro da Constituição Federal, legitimando a entidade familiar formada por um homem e uma mulher. Assim, a partir deste olhar é que percebo que o reconhecimento da união estável heterossexual também foi possível a

\footnotetext{
5 Referindo-se ao início do Século XX no Brasil, Susan K. Besse afirma que “(...) os direitos das mulheres pobres eram ignorados, - e muitas vezes gritantemente violados - por um estado autoritário, cada vez mais intervencionista, que procurava regulamentar sua saúde, reprodução, condições de vida e relações sociais, em nome do desenvolvimento econômico e da paz social” (BESSE, 1999, p. 224).

6 Art. 229 do Código Civil de 1916. Disponível em: planalto.gov.br. Acesso em: 01.03.2012.

7 Lei 9278, de 10 maio de 1996. Disponível em: planalto.gov.br. Acesso em: 01.03.2012.
} 
partir de um impulso judicial, pois foi em virtude de inúmeras decisões esparsas favoráveis ao reconhecimento que estas se transformaram em uma jurisprudência consolidada, o que possibilitou a alteração legislativa, passando da informalidade os concubinos e concubinas, amasios e amasias, para a formalidade, sob a égide da união estável.

Além do reconhecimento da família formada através da União Estável, a monoparentalidade, caracterizada como a "comunidade formada por qualquer dos pais e seus descendentes", também é reconhecida como uma forma de família pela Constituição da República Federativa do Brasil no artigo 226, $\$ 4^{\circ}$. Já multiparentalidade e pluriparentaridade ou famílias recompostas se caracterizam pela possibilidade de reconhecimento social e jurídico da família formada por dois pais ou duas mães, sendo um deles biológico e outro afetivo. Os divórcios e recasamentos permitem que se formem novas famílias, através de uniões livres, de coabitação, permitidos pela “reorganização e fragilização do laço conjugal” (UZIEL, 2007, p. 53). ${ }^{8}$

O ministro Luiz Fux, no termo aditivo $^{9}$ ao seu voto proferido na decisão do STF sobre a união estável entre pessoas do mesmo sexo, ao se perguntar sobre o "o que é uma família?” conclui que “(...) a Constituição Federal só consagrou a união estável porque $50 \%$ das famílias brasileiras são espontâneas", ou seja, a alteração da legislação brasileira apenas reconheceu a união estável devido ao fato de que esta forma de organização familiar é reconhecida no Brasil, estando apenas à margem do Estado.

\section{Viver em conjugalidade entre pessoas do mesmo sexo: é preciso mesmo casar no Brasil?}

A conjugalidade pode ser entendida como relações afetivo-sexuais, (...) que condensam "um estilo de vida", fundado em uma dependência mútua e em uma dada modalidade de arranjo cotidiano, mais do que propriamente doméstico, considerando-se que a coabitação não é regra necessária (HEILBORN, 2004, p. 11-12). 
Já Matos agrega a dimensão do afeto e do amor no conceito de conjugalidade, para quem esta pode ser considerada como:

(...) uma forma possível de gestão compartilhada da sexualidade e dos afetos, onde ideologias e práticas diversas de amor conjugal e de gênero se expressam e realizam, positivamente, um lócus ou uma cena onde se situam as trocas afetivas, sexuais e cognitivas entre os gêneros. (MATOS, 2000. p. 63)

Russel Parry Scott conceitua conjugalidade como

(...) o estabelecimento de ligações pretensamente duradouras de duas pessoas que praticam sexo e mantêm convivência cotidiana na esfera privada. A conjugalidade sugere a intenção de ter filhos e formar família, mas isso não é obrigatório para que sua existência se institua. Sugere também a coabitação, mas essa tampouco é obrigatória. (SCOTT, 2012, p. 495)

Segundo Russel Parry Scott, "a ideia da conjugalidade é central na formação da Antropologia como disciplina desde o século XIX, quando estudiosos tentaram explicar as diferentes formas de casamento e de relações de parentesco" (SCOTT, 2012, p. 495). As conjugalidades entre pessoas do mesmo sexo podem ser consideradas como um “fenômeno social típico das sociedades contemporâneas, resultado de uma luta política importante que vem sendo travada cotidianamente" (GROSSI, UZIEL, MELLO, 2007, p. 10).

Esta vivência da conjugalidade entre pessoas do mesmo sexo trata-se de um fenômeno que pode ser visibilizado nas sociedades contemporâneas, pois, como se percebe através das pesquisas de James Green e Eduardo Steindorf, que analisaram a homossexualidades masculinas no Brasil, era comum que gays vivenciassem casamentos heterossexuais e mantivessem relações homossexuais simultâneas. Segundo James Green, muitos homens mantinham uma relação de "casamento e os filhos, escapadas homossexuais à parte, tornam-se respostas às constantes pressões sociais para que constitua uma família e se conforme às normas sociais" (GREEN, 2000, p. 27) sendo que os sujeitos viviam a sua homossexualidade, em relacionamentos informais, o que o autor chamou de "escapadas", ou seja, concomitantemente ao relacionamento heterossexual, 
gays e lésbicas mantinham práticas sexuais homossexuais extraconjugais. Não especificamente em relação ao contexto brasileiro, Arnaud Lerch aponta que as profundas modificações nas formas de vivência das conjugalidades hétero e homossexuais nos últimos vinte anos, fez como que os homossexuais que viviam a sexualidade de maneira clandestina, distante do resto de sua vida social, pudessem experenciar um novo modelo de vida. Segundo Lerch "les avancées dans la reconaissance sociale et juridique des couples de même sexe depuis une dizaine d'années témoignent d'une aspiration croissante des gais à être e couple, en même temps qu'elles la nourrisent" ${ }^{10}$ (LERCH, 2008, p. 178, tradução nossa), sendo que esta mudança permite o desenvolvimento "une nouvelle normativité se développe peu à peu, donnant au couple un rôle privilégié dans l'affirmation do soi""11 (LERCH, 2008, p. 178, tradução nossa).

Não estou afirmando que a possibilidade de manter a vida sexual de forma clandestina não permaneça como um modelo nos dias atuais, mas que a pressão social para a constituição de uma família heterossexual, que impossibilitava a vivência conjugal homossexual era mais evidente em outros tempos, como apontam os pesquisadores citados. No mesmo sentido concluiu a tese de doutoramento de Eduardo Steindorf Saraiva, ao demonstrar a experiência de homens que após o casamento heterossexual se “assumiram” como gays. A partir da realização de entrevistas com homens adultos de 31 a 62 anos (SARAIVA, 2007, p. 40), o pesquisador demonstra que em relação à conjugalidade heterossexual não havia "quase nenhuma referência à escolha por amor. Já no segundo, homo, todas as referências são em relação ao amor e o desejo" (SARAIVA, 2007, p. 107). O que pretendo demonstrar, a partir das pesquisas citadas, é que em uma história recente homens e mulheres que se entendiam ou não como homossexuais, mantinham práticas sexuais com pessoas do mesmo sexo e, principalmente no contexto das classes médias brasileiras cediam às pressões familiares e à imposição ao casamento heterossexual como resposta a esta norma social, mesmo que permanecessem realizando suas "escapadas homossexuais", como caracterizou James

10 Os avanços no reconhecimento social e jurídico dos casais do mesmo sexo testemunham, há uns dez anos, de uma aspiração crescente dos homossexuais para formarem um casal, ao mesmo tempo que a alimentam.

11 Uma nova normatividade se desenvolve aos poucos, dando ao casal um papel privilegiado na afirmação de si. 
Green. Éric Fassin, ao fazer referência à "historiografia homossexual”, em seu texto, aponta a necessidade de se contar a história da homossexualidade, pois “ce n'est pas une même homosexulité qui traverse, immuable et inchangée, l’histoire: le mots pour la dire, que se métamorphosent au gré des époques, disent aussi une histoire de l'homossexualité ele-meme" (FASSIN, 2009, p. 99) ${ }^{12}$.

Se não é uma mesma homossexualidade que atravessa a história, também as formas de vivenciar as relações afetivo-conjugais sofreram transformações. Os estudos antropológicos sobre família e parentesco demonstram que no caso brasileiro "no campo dos estudos urbanos prevaleceu, neste mesmo período, o termo família para os estudos sobre parentesco em camadas médias e populares" (GROSSI, 2003, p. 276). Claudia Fonseca demonstra como os “"novos arranjos familiares' introduzem uma certa virada no antigo debate sobre consanguíneos versus afins na antropologia do parentesco". (FONSECA, 2008). A inclusão do termo família nos estudos sobre parentesco proporcionou um crescimento dos estudos que incluíram as conjugalidade entre pessoas do mesmo sexo. Assim "deixaram de ser invisíveis na bibliografia de referência sobre família e parentesco, em sociedades contemporâneas, como atestam várias publicações recentes" (GROSSI, 2003, p. 280). Em sua dissertação de mestrado, apresentada ao programa de Antropologia Social da Universidade Federal de Santa Catarina, Flávio Luiz Tarnovski, (2002, p. 47). ${ }^{13}$ ao estudar a conjugalidade e a família homossexual, utiliza os aportes da teoria da aliança de Lévi-Strauss e, a partir dessa teoria, conclui que "as relações homossexuais se caracterizariam por não terem a força de colocar em obrigação as famílias, pois, como não são relações reconhecidas publicamente, não teriam o poder de produzir alianças."

\footnotetext{
12 Não é uma homossexualidade idêntica que atravessa a história, imutável e não alterada: as palavras para dizê-las, se metamorfoseando ao belo prazer das épocas, contam também uma história da homossexualidade, elas próprias.

$13 \mathrm{Na}$ defesa da tese, Flávio Tarnovski se referiu a esta citação, trazendo ainda uma outra citação de seu próprio trabalho em que afirma "esse quadro, assim colocado não é, certamente o reflexo do que ocorre em todas as relações homossexuais, mas aponta para certas tendências recorrentes". Segundo o antropólogo, a pesquisa aqui apresentada permite afirmar que estas conjugalidades produzem sim alianças, chamando atenção para as afirmações que faço através de meus entrevistados/as os quais afirmam os vínculos entre as famílias, a circulação de bens e serviços, as ajudas, os favores ou trocas obrigações e reciprocidades dentre os casais e suas famílias de origem.
} 
A partir destes estudos antropológicos, percebo como estas conjugalidades passam a ser consideradas famílias, ao serem reconhecidas publicamente, corroborando aquilo que Bourdieu concluiu a respeito da família como uma invenção recente. Segundo Bourdieau "Famille que nous sommes portés à considérer comme naturelle est une invention récente (comme le montrent notamment les travaux d'Aries et d'Anderson sur la genèse du privé ou de Shorter sur l'invention du sentiment familial) qui est peut-être vouée à une disparition rapide" (1993, p. 32, tradução nossa) ${ }^{14}$. Mas ao contrário do que afirmou o sociólogo francês, o que se percebe, através da pesquisa realizada nesta tese, é que a família, além de não desaparecer no contexto brasileiro, incorporou novas possibilidades de grupos familiares.

Mesmo que o pai, a mãe e os filhos ainda constituem nosso "modelo ideal" de família na sociedade ocidental, este modelo é "cada vez mais uma experiência minoritária" (UZIEL, 2007, p. 20-21) o que se percebe diante da diversidade de novos arranjos familiares na contemporaneidade. As diversas formas de se relacionar em conjugalidade, como por duas pessoas do mesmo sexo, se contrapõe a este modelo de família no ocidente, principalmente a partir do final do século XVIII, reduzida a sua forma nuclear, formada pelo casal e seus filhos (DUARTE, 2012). Assim, ao passo que este aspecto relacional da família conviva com as trajetórias individuais de cada um dos seus membros, o pertencimento familiar continua sendo uma dimensão crucial da experiência social, como ensina Duarte (2012). Esta importância da família na experiência social, no contexto brasileiro, nos leva a pensar porque a família, ao contrário do que afirmou Bourdieu, ao invés de desaparecer é enaltecida, protegida e incentivada.

Esta centralidade da família fez com que as conjugalidade de pessoas do mesmo sexo pudessem passar de um modelo informal para um novo modelo que permite, inclusive, ser formalizado através do casamento civil. Assim como discuto a conjugalidade entre pessoas do mesmo sexo, utilizando os aportes da antropologia, é possível pensar no casamento como um dos sistemas de aliança possíveis, em que "a centralidade do casamento está associada a quase todas as teorias antropológicas clássicas, desde logo

\footnotetext{
14 A família que nós somos propensos a considerar como natural é uma invenção recente (como mostram em particular os trabalhos de Ariès e Anderson sobre a gênese do privado ou Shorter sobre a invenção do sentimento de família) que pode ser condenada a um rápido desaparecimento.
} 
as teorias da aliança que definem o casamento como forma de estabelecer alianças" (ALMEIDA, 2006, p.3).

Assim, a vivência da conjugalidade "que há algumas décadas pareceria um puro e simples paradoxo já que a identidade gay e o casamento eram visto como opostos" (MISKOLCl, 2007, p. 103), atualmente é marcada pela possibilidade do casamento, que, por sua vez, é marcado por um contexto histórico e social que proporcionou que estes casais passassem por um processo tanto de auto reconhecimento como pelo reconhecimento por parte de suas famílias de origem, dos amigos e colegas de trabalho (os quais serviram de prova testemunhal nos processos que analiso). Miguel Vale de Almeida afirma que "dizer e mostrar são, no campo da orientação sexual subalterna, os verdadeiros instrumentos políticos para a crítica e transformação do sistema homofóbico, para a obtenção de igualdade de direitos e para a famigerada transformação de mentalidades" (2010, p. 16).

O que proponho aqui é afirmar que mesmo que alguns sujeitos(as) ainda possam vivenciar práticas sexuais não heterossexuais não se assumindo como gays e lésbicas, ao mesmo tempo vivenciando relações heterossexuais, atualmente se tornou mais viável assumir a conjugalidade e reivindicar seu reconhecimento social e jurídico, inclusive através do casamento, que possibilita a visibilidade e publicidade das relações afetivosexuais de casais do mesmo sexo.

Proponho pensar que a exclusão e proibição ao "casamento como fundador de alianças e relações de afinidade" (ALMEIDA, 2006, p.3), como afirma Miguel Vale de Almeida, fez com que estes sujeitos(as) sofressem inúmeras formas de discriminações e alijamento de direitos. Através de uma perspectiva de busca por reconhecimento legal e jurídico, Miriam Grossi, Ana Paula Uziel e Luiz Mello afirmam sobre a conjugalidade LGBTTT. Segundo as pesquisadoras:

Discutir a conjugalidade LGBT por si só não cria realidades, mas seguramente põe em pauta situações diversas que precisam ser vistas em sua singularidade, ao mesmo tempo em que precisam ser reconhecidas como fenômeno social típico das sociedades contemporâneas, resultando de uma luta política importante que vem 
sendo travada cotidianamente por milhões de pessoas em todo 0 mundo. (GROSSI; UZIEL; MELLO, 2007, p.11)

Assim, se me aproprio dos conhecimentos da História e da Antropologia para pensar este artigo, também preciso me apropriar das definições da Ciência Jurídica, sobre o conceito de família e seus desdobramentos. Primeiramente, a família estava restrita ao casamento civil, para posteriormente este conceito ser alargado, por exemplo, com as relações reconhecidas como união estável, com famílias monoparentais e recompostas, que, no Brasil passam, também, a estar incluídas em um conceito de família a partir da Constituição de 1988, como apontarei a seguir.

Segundo Anna Paula Uziel (2007, p. 52) “a sacralidade da família nuclear talvez seja um dos impeditivos para a criação, até o momento, de termos que expressem a pluralidade de laços". A família formada através do casamento civil é imposta como modelo tanto pela Ciência Jurídica, como por diversas religiões, que impedem ou não reconhecem estes novos arranjos familiares. "A diversidade das estruturas e configurações familiares na passagem do século XX, demonstrando a imensa plasticidade dos grupos domésticos e das múltiplas possibilidades de organização da reprodução biológica e social em uma mesma sociedade" (MELLO, 2005a, p. 29). Isso reitera o que observei sobre a concomitância de modelos familiares.

Entretanto, a Constituição Federal de 1988 reconheceu legalmente outras formas de família, concedendo proteção às mesmas, "independente da celebração do casamento". Para Maria Berenice Dias (2006, p. 116), esse conceito poderia albergar “diferentes vínculos afetivos: tanto a união estável entre um homem e uma mulher, como as relações de um dos ascendentes com sua prole, passaram a configurar como família". Para ela, com a Constituição de 1988, “o conceito de família alargou-se” (DIAS, 2006, p. 128) e, "para a configuração de uma entidade familiar, não é mais exigida, como elemento constitutivo, a existência de um casal heterossexual, a prática sexual e a capacidade reprodutiva" (DIAS, 2006, p. 128). A partir desse instrumento legal, é inserido na 
legislação brasileira o conceito de entidade familiar que engloba a família monoparental ${ }^{15}$ e a formada através da união estável ${ }^{16}$.

No tratado internacional denominado de "Princípios de Yogyarkarta”, o princípio de número 24 reconhece o "direito de constituir família”, nestes termos: "Toda pessoa tem o direito de constituir uma família, independente de sua orientação sexual ou identidade de gênero. As famílias existem em diversas formas. Nenhuma família pode ser sujeita à discriminação com base na orientação sexual ou identidade de gênero de qualquer de seus membros". E em relação aos Estados, o tratado internacional assim disciplina em relação ao reconhecimento da família formada por pessoas do mesmo sexo,

e) Tomar todas as medidas legislativas, administrativas e outras medidas necessárias para garantir que, nos Estados que reconheçam a parceria registrada entre pessoas do mesmo sexo, qualquer prerrogativa, privilégio, obrigação ou benefício disponível para pessoas casadas ou parceiros/as registrados/as de sexo diferente esteja igualmente disponível para pessoas casadas ou parceiros/as registrados/as do mesmo sexo." ${ }^{17}$

Percebo a reivindicação dos homossexuais como "C'est la revendication des homosexuels qui vient renouveller le débat sur la modernité de la famille: la demande d'égalité entre les sexualités pose ainsi desc questions quie touchent à la definition même de la societé" (BORRILO, FASIN, 1999, p. 4, tradução nossa). ${ }^{18}$ Se, como sugerem Borrilo e Fassin, este casais de pessoas do mesmo sexo propõem uma nova roupagem ao conceito de família, estas têm o condão de modificar as definições sociais do que é considerado família.

Assim, não estou tentando identificar uma "modalidade 'alternativa' de família" (MELLO, 2005a, p. 75), como sugeriu Luiz Mott, ou uma outra forma de entidade familiar ou um quarto gênero ${ }^{19}$ como definiu o ministro Ricardo Lewandowski, ou as tratando

\footnotetext{
15 A família monoparental é aquele formada pela mãe ou pelo pai e seus filhos, conforme artigo 226, parágrafo quarto da Constituição Federal.

16 O conceito de união estável e sua fundamentação legal será trazida ainda neste capítulo.

17 Disponível em: http://www.clam.org.br/pdf/principios_de_yogyakarta.pdf. Acesso em: 10 abr. 2013.

18 Trata-se da reivindicação dos homossexuais que vem relançar o debate sobre a modernidade da família: a demanda por igualdade entre as sexualidades coloca, portanto, questões que dizem respeito à própria definição da sociedade.

19 Brasil, STF, ADI 4277, Voto do Senhor Ministro Ricardo Lewandowski, 2011, p. 6.
} 
como novas famílias ou famílias homoafetivas, mas sim de que estas conjugalidades, a partir da possibilidade de serem registradas através da união estável ou do casamento civil, são incluídas num conceito legal de família, pois informalmente, não integralmente e não da mesma forma em todos os contextos, já havia um certo reconhecimento social dos vínculos afetivo-sexuais entre pessoas do mesmo sexo.

O que pretendo observar neste artigo são as implicações entre a inclusão neste modelo de família previsto na legislação e o reconhecimento social da conjugalidade entre pessoas do mesmo sexo pela sociedade. É importante observar que a cultura brasileira é marcada por improvisações e informalidades nos laços familiares, pois mesmo os que vivem juntos sem a exigência de formalidade são considerados casados.

Como se dará este reconhecimento social como família, já que é sabido que a mudança legislativa nem sempre é acompanhada de um reconhecimento social? O que precisa ser modificado para o reconhecimento social destas famílias? Elas precisam ser incluídas neste conceito de família ou são mesmo uma modalidade alternativa ou um quarto gênero de família? Estas e outras devem ser respondidas ao tratar da temática da conjugalidade de pessoas do mesmo sexo e sua inclusão no conceito de família.

\section{Finalizando...}

Este artigo reflete sobre as disputas em torno do conceito de família. Este tema foi utilizado como eixo estruturante de outras pesquisas para a temática da conjugalidade entre pessoas do mesmo sexo, como a de Luiz Mello, no Brasil, José Ignacio Pichardo Gálan, na Espanha e Miguel Vale de Almeida, em Portugal.

O que pude perceber ao longo da trajetória da pesquisa que realizei durante o doutorado, a partir da realização de entrevistas, é que, diferentemente do que demanda o movimento LGBTTT, muitos casais não se reconhecem como família, e esta não parece se configurar como uma categoria importante nestas relações conjugais. Muitos dos casais, ao serem interrogados sobre seu conceito de família, me devolveram a pergunta, questionando o que era família para mim. Outros não entendiam o que eu pretendia com este questionamento. Concluo que, para muitos casais de pessoas do mesmo sexo, ser considerados ou não como família, realizar o registro ou não, casar ou não, não faz a 
menor diferença para seus cotidianos pessoais e afetivos. Assim, mesmo sabendo que o casamento é uma instituição de grande importância para as configurações familiares no Brasil, muitos deles, mesmo sem estarem casados legalmente, se consideram casados por viverem em conjugalidade. Esta constatação me faz refletir que as conjugalidades de pessoas do mesmo sexo no Brasil, se formam a partir do que nos ensina a historiadora Maria Odila Leite da Silva Dias (1994) como sendo “improvisações" de conjugalidade. Estas são consideradas também como uma nova modalidade de arranjo familiar, como propõe Claudia Fonseca (2008). O que observamos é que há, neste contexto, um reconhecimento social de relações conjugais informais, que permitiu, por exemplo, que o texto constitucional determinasse que a lei deve "facilitar a conversão da união estável em casamento". ${ }^{20}$

Ou seja, o contexto brasileiro é marcado pela não formalização das relações conjugais. Ou seja, mesmo que não atravessados pela normalização estatal, seja através de uma declaração de união estável ou por um contrato civil de casamento, estes casais se sentem e se declaram como "casados" e "casadas". Percebi então, que este reconhecimento como família era importante quando se buscava a concessão de direitos, o reconhecimento da conjugalidade por meio da justiça, ou no contexto da militância LGBTTT. Assim, nestes contextos em que se fazia necessário a prova de uma relação conjugal estável para a demanda por direitos, a única via possível para o reconhecimento do Judiciário era através do enquadramento destes casais no conceito de família.

Não quero dizer aqui que algumas pessoas não estão preocupadas com 0 reconhecimento como famílias, ou que estas não tem consciência de seus direitos. Talvez esse discurso familista seja próprio das políticas públicas e utilizado pela militância, com o objetivo de reforçar a busca por direitos. Mas que o que eu compreendi é que o reconhecimento como família ou o que representa "ser uma família" para estes casais, é diferente do que consideram estar "casados" ou "casadas". Ou seja, na nossa cultura basta que um casal more junto para que sejam considerados casados ou casadas, independentemente de qualquer registro em cartório, da certidão de união estável ou de casamento, ou de qualquer outra formalidade.

20 Artigo 226, § 3 da Constituição Federal. Disponível em: www.planalto. gov.br. Acesso em: 1 abr. 2013. 
O que é possível perceber é que as relações afetivo-conjugais, sejam elas hetero ou homossexuais, muitas vezes são marcadas pela improvisação e pela informalidade, e somente no momento de um infortúnio ou de uma necessidade é que se busca um reconhecimento jurídico daquela relação conjugal que já foi reconhecida pelo meio social. Também é importante ressaltar que muitos indivíduos só sentem a necessidade de comprovação ou de regulação a partir de uma necessidade, como o caso da morte de um dos companheiros/as, e somente a partir daí é que "procuram seus direitos"..

Assim, alguns casais não pretendem ser reconhecidos como família, mas preservam uma ideia de que a conjugalidade entre pessoas do mesmo sexo tem uma postura libertária, não conservadora, proposta pela teoria queer (BUTLER, 2003). Observamos aqui o papel que a crítica realizada pelos teóricos queer, em relação à judicialização do casamento entre pessoas do mesmo sexo tem eco entre estes casais.

Por outro lado as diversas práticas de vivência das sexualidades, principalmente as homossexualidades, podem a partir de uma perspectiva democrática, possibilitar a concessão de direitos. A democracia sexual permite que as mudanças na esfera da sexualidade não se limitem ao campo dos costumes, tampouco de uma moral individual, mas sim a partir de uma politização.

\section{Referências Bibliográficas}

ALMEIDA, Miguel Vale de. Dos na China aos gays de Lisboa. Apresentado no Ciclo de conferências "A Tempestade e o Copo d'Água”, org. Livraria Almedina e Miguel Vale de Almeida, 30 nov. 2006. Disponível em: http://site.miguelvaledealmeida.net/wpcontent/uploads/dos-na-da-china1.pdf. Acesso em: 1 jul. 2010.

ALMEIDA, Miguel Vale de. O casamento entre pessoas do mesmo sexo. Sobre gente "remotas e estranhas" numa "sociedade decente". In: GROSSI, Miriam Pillar; UZIEL, Anna Paula; MELLO, Luiz (Org.). Conjugalidades, parentalidades e identidades lésbicas, gays e travestis. Rio de Janeiro: Garamond, 2007, p. 153-168.

ALMEIDA, Miguel Vale de. A chave do armário: homossexualidade, casamento e família. Florianópolis: Ufsc, 2010.

AREND, Silvia Maria Fávero. Amasiar ou Casar? a família popular no final do século XIX. Porto Alegre: Universidade/UFRG, 2001. 
BASSANEZI, Carla. Virando as páginas, revendo as mulheres: relações homem-mulher e revistas femininas, 1945-1964. 1. ed. Rio de Janeiro: Civilização Brasileira, 1996.

BESSE, Susan K. Modernizando a desigualdade: reestruturação da ideologia de gênero no Brasil, 1914-1940. Trad. Lólio Lourenço de Oliveira. São Paulo: Universidade de São Paulo, 1999.

BORRILLO, Daniel; FASSIN, Eric. Au-delá du PaCS: L'expertise familiale à l'épreuve de I’homosexualité. Paris: Presses Universitaires de France, 1999.

BOURDIEU, Pierre. À propos de la famille comme catégorie réalisée. Persee Revues Scientifiques, v. 100, p. 32-36, 1993.

BUTLER, Judith Problemas de gênero: feminismo e subversão da identidade. Rio de Janeiro: Civilização Brasileira, 2003a.

BUTLER, Judith..Tráfico Sexual: entrevista com Gayle Rubin. Cardernos Pagu, São Paulo, Campinas, vol. 21, 2003b.

DIAS, Maria Berenice. Manual de direito das famílias. 3. ed. São Paulo: Revista dos Tribunais, 2006.

DIAS, Maria Odila Leite da Silva. Novas subjetividades na pesquisa histórica feminista: uma hermenêutica das diferenças. Estudos Feministas, Florianópolis, v.2, n. 2, 1994, p. 373382.

DUARTE, Luiz Fernando Dias. "Nós na família”. Ciência Hoje, 1 jun. 2012. Disponível em: <http://cienciahoje.uol.com.br/colunas/sentidos-do-mundo/nos-na-familia>.

ESTEVES, Martha de Abreu. Meninas perdidas: os populares e o cotidiano do amor no Rio de Janeiro da belle époque. Rio de Janeiro: Paz e Terra, 1989.

FASSIN, Eric. Le sexe politique: Genre et sexualité au miroir transatlantique. Paris: Editions de l'École des Hautes Études em Sciences Sociales, 2009.

FINE, Agnés; MARTIAL, Agnés. Anthropolgie et roman. À propôs des péres divorcés. Ethnologie française, v. 42, p. 155-164, jan./jul. 2012.

FRASER, Nancy. Redistribuição, reconhecimento e participação, por uma concepção integrada de justiça. In: SARMENTO, Daniel; IKAWA, Daniela; PIOVESAN, Flávia. Igualdade, diferença e direitos humanos. Rio de Janeiro: Lumen Juris, 2010. 
FONSECA, Cláudia. Cavalo amarrado também pasta: honra e humor em um grupo popular brasileiro. Revista Brasileira de Ciências Sociais, ano 6, n. 15, fev. 1991, p. 01-19.

FONSECA, Cláudia.. Quando cada caso não é um caso: pesquisa etnográfica e educação. Trabalho apresentado na XXI Reunião Anual da ANPEd, Caxambu, setembro de 1998, p. 58-78.

FONSECA, Cláudia.. Caminhos da Adoção. 2 ed. São Paulo: Cortez, 2002.

FONSECA, Cláudia..Sexualidade, família e legalidade: questionando fronteiras. In: ÁVILA, Maria Betânia; PORTELLA, Ana Paula; FERREIRA, Verônica. Novas legalidades e democratização da vida social: família, sexualidade e aborto. Rio de Janeiro: Garamond, 2005a. p. 53-64.

FONSECA, Cláudia.. Concepções de família e práticas de internveção: uma contribuição antropológica. Saúde e Sociedade. 2005b, v.14, n.2, p. 50-59.

FONSECA, Cláudia.. Homoparentalidade: novas luzes sobre o parentesco. Estudos Feministas. 2008, v.16, n.3, p. 769-783.

FOUCAULT, Michel. História da sexualidade: a vontade de saber. Rio de Janeiro: Graal, 1988.

GALÁN, José Ignacio Pichardo. Espagne. Le mariage homosexuel au pays de la famille. In: DESCOUTURES, Virginie, et al. Mariage et homossexualités dans le monde: L'arrangement des norms familiales. Paris: Autrement, 2008, p. 62-72.

GALÁN, José Ignacio Pichardo. Entender la diversidade familiar: relaciones homosexuales y nuevos modelos de família. Barcelona: Bellaterra, 2009.

GOLDBERG, Anette. Feminismo e Autoritarismo: a metamorfose de uma utopia de liberação em ideologia liberalizante. 1987. 217 p. Dissertação (Mestrado) - Universidade Federal do Rio de Janeiro. Instituto de Filosofia e Ciências Sociais, Mestrado em Ciências Sociais, Rio de Janeiro, 1987 (Mimeografado).

GREEN, James Naylor. Além do carnaval: a homossexualidade masculina no Brasil do século XX. São Paulo: Unesp, 2000.

GROSSI, Miriam Pillar. Gênero e parentesco: famílias gays e lésbicas no Brasil. Cadernos Pagu, Campinas, n. 21, p. 261-280, 2003. 
GROSSI, Miriam Pillar; UZIEL, Anna Paula; MELLO, Luiz (Org.). Conjugalidades e parentalidades de gays, lésbicas e transgêneros no Brasil. Estudos Feministas, Florianópolis, v. 14, n. 2, Dossiê, maio/set. 2006, p. 481-547.

GROSSI, Miriam Pillar; UZIEL, Anna Paula; MELLO, Luiz (Org.). Conjugalidades, parentalidades e identidades lésbicas, gays e travestis. Rio de Janeiro: Garamond, 2007.

HEILBORN, Maria Luiza. Dois é par: gênero e identidade sexual em contexto igualitário. Rio de Janeiro: Garamond, 2004.

LERCH, Arnaud. Réécrire le script ? Conjugalité et sexualité dans les couples gais non exclusifs. Mariages et homossexualités dans le monde: l'arrangement des normes familiales. Paris: Autrement, 2008, n. 244, p. 177-188. MADALENO, Rolf. Curso de direito de família. Rio de Janeiro: Forense, 2011.

MATOS, Marlise. Reinvenções do vínculo amoroso: cultura e identidade de gênero na modernidade tardia. Belo Horizonte: UFMG; Rio de Janeiro: IUPERJ, 2000.

MELLO, Luiz. Novas famílias: conjugalidade homossexual no Brasil contemporâneo. Rio de Janeiro: Garamond, $2005 a$.

MELLO, Luiz.. Outras famílias. A construção social da conjugalidade homossexual no Brasil. Cadernos Pagu, Campinas, n. 24, p. 197-225, jan/jun. 2005b.

MELLO, Luiz..Matrimônio entre pessoas do mesmo sexo na Espanha. Do perigo social à plena cidadania em quatro estações. In: Conjugalidades, parentalidades e identidades lésbicas, gays e travestis. Rio de Janeiro: Garamond, 2007, p. 169-188.

MISKOLCl, Richard. Pânicos Morais e Controle Social: reflexões sobre o casamento gay Cadernos Pagu. Campinas, 2007. v.28. p.101-128.

NICHNIG, Claudia Regina. Entre igualdades e diferenças: mudanças nas legislações referentes às mulheres (1975-1985). Dissertação de Mestrado. Programa de PósGraduação em História. Universidade Federal de Santa Catarina, 2008.

NICHNIG, Claudia Regina. Mulher, mulheres, mulherio: discursos, resistência e reivindicações por direitos. Rio de Janeiro: Multifoco, 2013.

SARAIVA, Eduardo Steindorf. Conjugando amor e desejo: experiências masculinas do "assumir-se" homossexual. Tese (Doutorado). Universidade Federal de Santa Catarina, Centro de Filosofia e Ciências Humanas. Programa de Pós-Graduação Interdisciplinar em Ciências Humanas, 2007. 
SARTI, Cynthia Andersen. A família como espelho: um estudo sobre a moral dos pobres. São Paulo: Editora Cortez; 2005.

SCOTT, Russel Parry. Relações conjugais em transformação. In: Antonio Carlos de Souza Lima. (Org.). Antropologia \& Direito: Temas antropológicos para estudos jurídicos. Rio de Janeiro: Brasília: Contra Capa, LACED, Associação Brasileira de Antropologia, 2012, p. 495509. SILVA, Marcos Alves da. Da monogamia: a superação como princípio estruturante do Direito de Família.Curitiba: Juruá, 2013

TARNOVSKI, Flávio Luiz. Pais assumidos: adoção e paternidade homossexual no Brasil contemporâneo. Dissertação de Mestrado. Antropologia Social da Universidade Federal de Santa Catarina, Florianópolis, 2002.

UZIEL, Ana Paula; MELLO, Luiz; GROSSI, Miriam Pillar. Conjugalidades e parentalidades de gays, lésbicas e transgêneros no Brasil. Estudos Feministas, v. 14, p. 481-487, $2006 a$.

UZIEL, Ana Paula; MELLO, Luiz; GROSSI, Miriam Pillar. Adoção e homossexualidade: aos autores e seus produtos. Uma análise da entrevista e seus processos. Rio de Janeiro: Garamond, 2007.

VENOSA, Silvio de Salvo. Direito Civil: Família. São Paulo: Editora Atlas, 2005. 